\title{
A population dynamic approach to evaluating the impact of school attendance on the unit cost and effectiveness of school-based schistosomiasis chemotherapy programmes
}

\author{
H. CARABIN*, M.-S. CHAN and H. L. GUYATT \\ The Wellcome Trust Centre for the Epidemiology of Infectious Disease, University of Oxford, South Parks Road, \\ Oxford OX1 $3 F Y, U K$
}

(Received 11 December 1999; revised 4 February 2000; accepted 4 February 2000)

\begin{abstract}
S U M M A R Y
This paper presents a first attempt at modelling the possible cost and effectiveness of reaching non-enrolled children through school-based programmes using empirical data from Egypt. A sex/school-attendance/age-structured population dynamic model was used to predict trends in infection and early disease. Four treatment delivery strategies were compared: school-based (coverage of $85 \%$ ) and school-aged targeted (coverage of 25, 50 and $85 \%$ ). The school-aged targeted strategies also included the school-based programme. For each alternative strategy, the maximum unit cost was calculated to obtain a cost-effectiveness ratio equal or smaller to the one obtained with the school-based programme (unit cost of US\$ 0.60). The analysis showed that, for $S$. mansoni in Lower Egypt, a programme where only $85 \%$ of children attending school were treated would still prevent $77 \%$ of the early disease cases prevented with a programme where $85 \%$ of all school-age children were treated. However, using the school-aged targeted strategy, from US\$0.06 to US\$1.03 extra unit costs could be spent to reach non-enrolled children and still be more cost-effective. Treating non-enrolled children is an important consideration in maximizing the effectiveness of treatment programmes while maintaining a cost-effectiveness comparable to school-based delivery.
\end{abstract}

Key words: schistosomiasis, population dynamic model, school attendance, school-aged children, chemotherapy, costeffectiveness analysis.

\section{INTRODUCTION}

School-based anthelmintic programmes are becoming increasingly popular as a means of controlling intestinal nematode infections and schistosomiasis (Hall et al. 1997; Partnership for Child Development, 1997; Savioli et al. 1997). The impetus to this initiative has been the relative ease and cost reductions in using schools to deliver treatment, and the relative effectiveness in targeting the segment of the population most at risk of heavy infection and disease (Anderson \& May, 1985), with spin-offs for reducing transmission in the rest of the community (Bundy et al. 1990; Butterworth et al. 1991; Chan et al. 1994, 1995, 1998). One major concern, not just in terms of the effectiveness of these programmes, but also in terms of equity is that such a delivery strategy will not reach the large number of school-aged children who are not enrolled or do not attend school. In Africa in 1996, gross enrolment ratios in primary school males and females were $85.3 \%$ and $71.2 \%$, respectively (United Nations Education, Scientific and Cultural Organization, 1998). These children not enrolled will be missed by a school-

* Corresponding author. Tel: + 44 (0) 1865281 880. Fax: +44 (0) 1865 281245. E-mail: helene.carabin@ ceid.ox.ac.uk based initiative though they are equally and may in some instances be at higher risk of disease than those children at school. Indeed, recent studies in Africa showed that school-aged children not enrolled in school had a higher prevalence and intensity of both Schistosoma mansoni and S. haematobium infection than those children enrolled (Husein et al. 1996; Hammad et al. 1997; Useh \& Ejezie, 1999; Gyorkos, personal communications). Reaching these out-ofschool children could be achieved by community based control efforts or by encouraging school-aged children not-enrolled to receive treatment from the school setting, as has already been reported in Egypt (Talaat, Omar \& Evans, 1999). Both these control effects would require extra costs, not only in providing additional anthelmintic treatments, but also extra delivery costs in locating these individuals or encouraging them to attend a treatment site.

In the absence of intervention trials to evaluate the relative cost and effectiveness of these alternative control efforts, mathematical modelling can provide useful insights into the predicted patterns. Modelling also lends itself to extensive sensitivity analysis to explore the impact under conditions varying in epidemiology (for instance, infection levels in enrolled and non-enrolled children), coverage, drug efficacy and unit costs for treatment and delivery 
which exist in different localities (Guyatt, 1998; Guyatt \& Chan, 1998; Chan et al. 1998). Population dynamic models of helminth infection have been used to evaluate the impact of school-based treatment strategies (Guyatt \& Chan, 1998; Guyatt, 1999), but these have not considered the potential differences in infection levels of children in and out of school.

In this paper we present a population dynamic model for schistosomiasis which captures these differences by explicitly considering school-aged children in and out of school as discrete segments of the population. Since infection levels can also vary with sex (Gyorkos et al. 1995; Hammad et al. 1996; Husein et al. 1996; Montesor et al. 1997; Useh \& Ejezie, 1999), these groups are further stratified into boys and girls. Using the published empirical data from studies in Egypt (Husein et al. 1996; Talaat et al. 1999), we explore the effectiveness of schoolbased strategies in comparison with school-aged targeted in this setting.

\section{MATERIALS AND METHODS}

\section{Empirical data and study population}

The data on the prevalence of infection and school enrolment proportions were taken from a large-scale study conducted in Egypt in 1990 as part of Egypt's Schistosomiasis Research Project (Barakat et al. 1995; El Khoby, Galal \& Fenwick, 1998). This survey was conducted in rural areas of 9 governorates -4 Lower Egypt governorates, recognized as endemic for S. mansoni, and 5 Upper Egypt governorates, recognized as endemic for $S$. haematobium (Husein et al. 1996). The primary sampling unit was the village and a representative sample of all gender-age groups was obtained (Barakat et al. 1995). All members of selected households were invited to participate in the study by providing stool and urine specimens (Husein et al. 1996). The data on age, sex and school attendance for children aged 6-15 years were collected from each individual of the household (or their mothers if children were less than 12 years old). A child was defined as nonenrolled if she/he declared to never have attended school or to have stopped going to school. The presence of infection was measured using the nucleopore filter technique for urine samples and the quick Kato smear for stool samples (Barakat et al. 1995).

Table 1 summarizes the school enrolment figures and the prevalences of $S$. mansoni and $S$. haematobium reported by the authors and stratified by sex and school enrolment (Husein et al. 1996). These parameters are used in the model to establish the equilibrium condition (i.e. the levels of infection in the different subgroups of the population before treatment).

\section{The model}

The model is a modification of an age-structured population dynamic model that has been described elsewhere (Chan et al. 1995, 1996a,b). Briefly, this model assessed the instantaneous change in worm burden in different age groups, and included parameters describing the density-dependent mechanism (the establishment rate of new adult worms decreases as the worm burden increases) and the immune response of individuals at each age based on the previous mean worm burden in that group.

In the current model, the transmission dynamics are assumed to differ by sex and school attendance. The population is stratified into 4 groups $(g)$ representing the populations of females in school $(g=1)$, males in school $(g=2)$, females out of school $(g=3)$ and males out of school $(g=4)$. The instantaneous change in the mean worm burden for individuals of age $(a)$ in group $(g)$ is determined by the number of new infections $(\Lambda(g, a, t))$ during a very short period of time $(\Delta t)$, weighted by immunity response $\left(\mathrm{e}^{-\delta I(g, a, t)}\right)$ minus the sum of the number of deaths of adult worms $(\mu M(g, a, t))$ during that period. The sum of the worm burden over all ages $(a)$ and groups $(g)$ at time $(t)$ is used to evaluate the number of new infections in each group $(g)$ depending on group and age specific contact and contamination rates. In other words, all 4 groups are exposed to a common infection source in the environment, but will acquire the infection and in turn contaminate the environment at different rates. The mixing between groups is considered random. The model is described in detail in Appendix 1. The parameters relating to these biological processes are given in Appendix 2.

It is assumed that there is a total population of 100000 . The proportion of the population in and out of school, by sex, is different in the two regions where $S$. haematobium and $S$. mansoni are endemic. The age distribution was, however, assumed to be the same for males and females, in and out of school, and to be based on a negative exponential distribution and parameter values for the Middle-East, as suggested in the World Bank 'Global Burden of Disease' study (Murray, 1996). For a population with $n_{g}$ individuals in group $(g)$, the number of individuals of age $(a)$ is

$n_{a, g}=0 \cdot 0356 n_{g} \mathrm{e}^{-0 \cdot 33 a}$.

\section{The control programmes and measuring effectiveness}

Two main strategies are compared: school-based (where only enrolled children are treated) and school-aged targeted (where non-enrolled children are also treated). The treatment is assumed to immediately reduce the mean worm burden in each group by a percentage defined by the coverage in each group multiplied by the drug efficacy (assumed 
Table 1. The empirical data on study population and prevalence of Schistosoma mansoni and Schistosoma haematobium in females and males in and out of school in Upper and Lower Egypt

\begin{tabular}{|c|c|c|c|c|c|c|}
\hline & \multicolumn{3}{|c|}{ Schistosoma mansoni } & \multicolumn{3}{|c|}{ Schistosoma haematobium } \\
\hline & $\begin{array}{l}\text { Study } \\
\text { population }\end{array}$ & $\begin{array}{l}\text { Num } \\
\text { exam }\end{array}$ & $\begin{array}{l}\text { Prevalence } \\
\mathrm{d}(\%)\end{array}$ & $\begin{array}{l}\text { Study } \\
\text { population }\end{array}$ & $\begin{array}{l}\text { Number } \\
\text { examined }\end{array}$ & $\begin{array}{l}\text { Prevalence } \\
(\%)\end{array}$ \\
\hline \multicolumn{7}{|l|}{ Females } \\
\hline Enrolled & 5783 & 5079 & $1474(29 \cdot 0)$ & 2596 & 4353 & $581 \quad(5 \cdot 0)$ \\
\hline Not enrolled & 2127 & 1876 & $722(38 \cdot 5)$ & 4156 & 1750 & $401(14 \cdot 0)$ \\
\hline \multicolumn{7}{|l|}{ Males } \\
\hline Enrolled & 6887 & 6001 & $2538(42 \cdot 3)$ & 5265 & 2118 & $105(13 \cdot 3)$ \\
\hline Not enrolled & 1316 & 1130 & $536(47 \cdot 4)$ & 2179 & 3399 & $476(22.9)$ \\
\hline
\end{tabular}

Data taken from Husein et al. (1996).

to $90 \%$ ). Annual treatment is administered over a 5 year programme (a total of 5 treatments).

Effectiveness is assessed as the reduction in the number of infections or in the number of early disease cases (hepatomegaly for $S$. mansoni and upper urinary tract pathology for $S$. haematobium) over 15 years for the 5 years during intervention and for 10 years following) (Chan et al. 1996a). The dynamics of the development, resolution and the effect of treatment on early disease have been explained elsewhere (Chan et al. 1996a, b; Chan \& Bundy, 1997). Briefly, the number of new cases of early disease depends on the mean worm burden in group $(g)$ of age $(a)$ at time $(t)$. Fig. 1 illustrates the changes by age groups in the prevalence of $S$. mansoni infection for males in school (B), males out of school (D), females in school (A) and females out of school (C) after a school-based treatment with coverage of $85 \%$.

The number of cases prevented is measured by the difference between the number of infected (or early disease cases) at equilibrium (before the first round of treatment) and the number of infected (or early disease cases) each year after treatment. To account for the fact that a case prevented today is preferable to a case prevented in the future, a discount rate of $5 \%$ was applied to the number of cases prevented for each of the 15 years after the first round of treatment. The overall effectiveness is measured as the sum of the discounted cases prevented over 15 years. The relative increase in effectiveness was calculated as the ratio between the number of cases prevented with each of the 5 alternative strategies compared with the school-based strategy. The relative number of individuals treated was also calculated.

\section{Simulations}

Coverage in school is assumed to be $85 \%$ (Nokes \& Bundy, 1993; Hall, personal communication, 1999) and only children aged $6-15$ are treated. The coverage in children out of school is varied from zero (school-based programme), to a proportion close to that observed when a programme was implemented to encourage children out of school to come to school to be treated $(85 \%$ - school-aged targeted programme) (Talaat et al. 1999). The different control strategies assessed are presented in Table 2.

\section{Cost-effectiveness analysis}

Analysis is undertaken to explore the maximum unit cost required for one strategy to be as or more costeffective than another strategy. Let $x$ and $y$ be the school-based and school-aged targeted control programmes. Each programme will incur a total $\operatorname{cost} C_{j}$ $(j=x$ or $y)$ (including the delivery costs) and have an effectiveness of $E_{j}$ (number of discounted early disease or infection cases prevented over 15 years). The aim is to estimate the cost of the alternative strategies compared to the commonly implemented school-based strategy. Programme $y$ will be as or more cost-effective as programme $x$ if:

$\frac{C_{y}}{E_{y}} \leqslant \frac{C_{x}}{E_{x}}$.

Let $N_{i}$ represent the number of individuals in each group, $V_{i}$ the coverage and $i=s$ for children in school and $i=n e$ for school-aged children not in school. Defining $U_{i}$ as the unit cost of treatment (cost per individual, including delivery), the total costs for programmes $x$ and $y$ can be calculated as:

$C_{x}=U_{s} N_{s} V_{s}$

$C_{y}=U_{s} N_{s} V_{s}+U_{n e} N_{n e} V_{n e}$.

The threshold unit cost (maximal unit cost) to reach and treat individuals not-enrolled in school while maintaining programme $y$ to be as or more costeffective than programme $x$ is given by:

$U_{n e} \leqslant\left(\frac{E_{y}}{E_{x}}-1\right)\left(\frac{U_{s} N_{s} V_{s}}{N_{n e} V_{n e}}\right)$.

The difference between the maximal unit cost $\left(U_{n e}\right)$ and the unit cost for the school-based programme $\left(U_{s}\right)$ indicates the maximal extra unit cost that could be spent to treat individuals not enrolled and obtain a strategy as cost-effective as the school-based programme. 

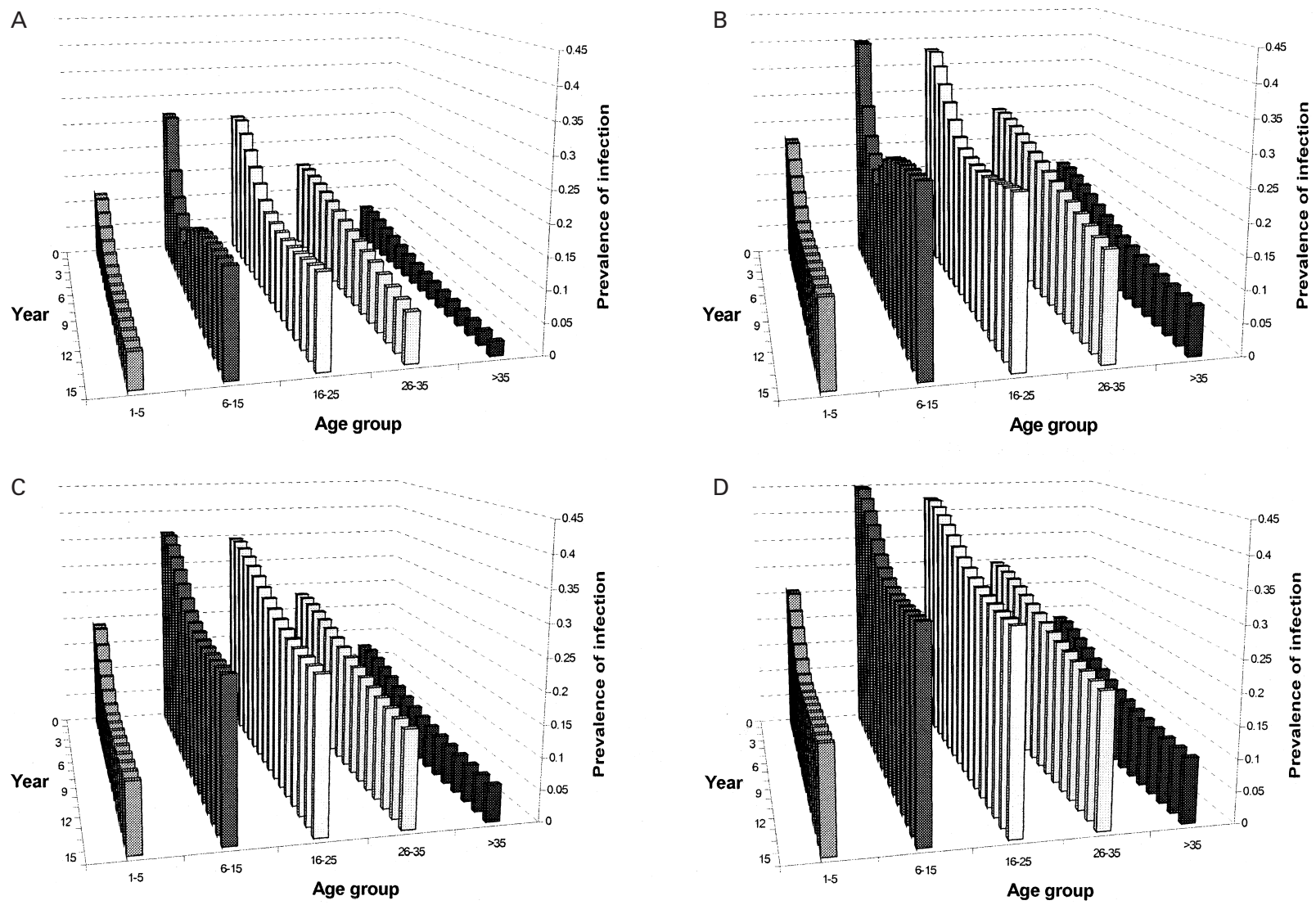

E

$\mathrm{F}$
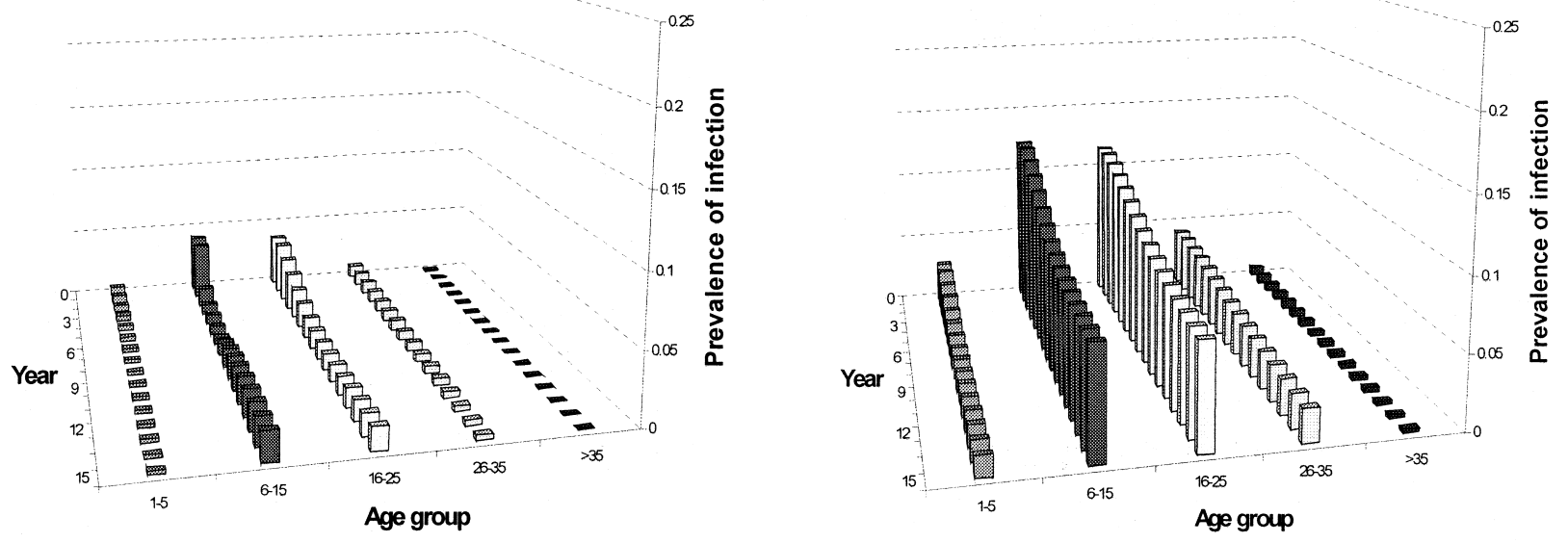

G

$\mathrm{H}$
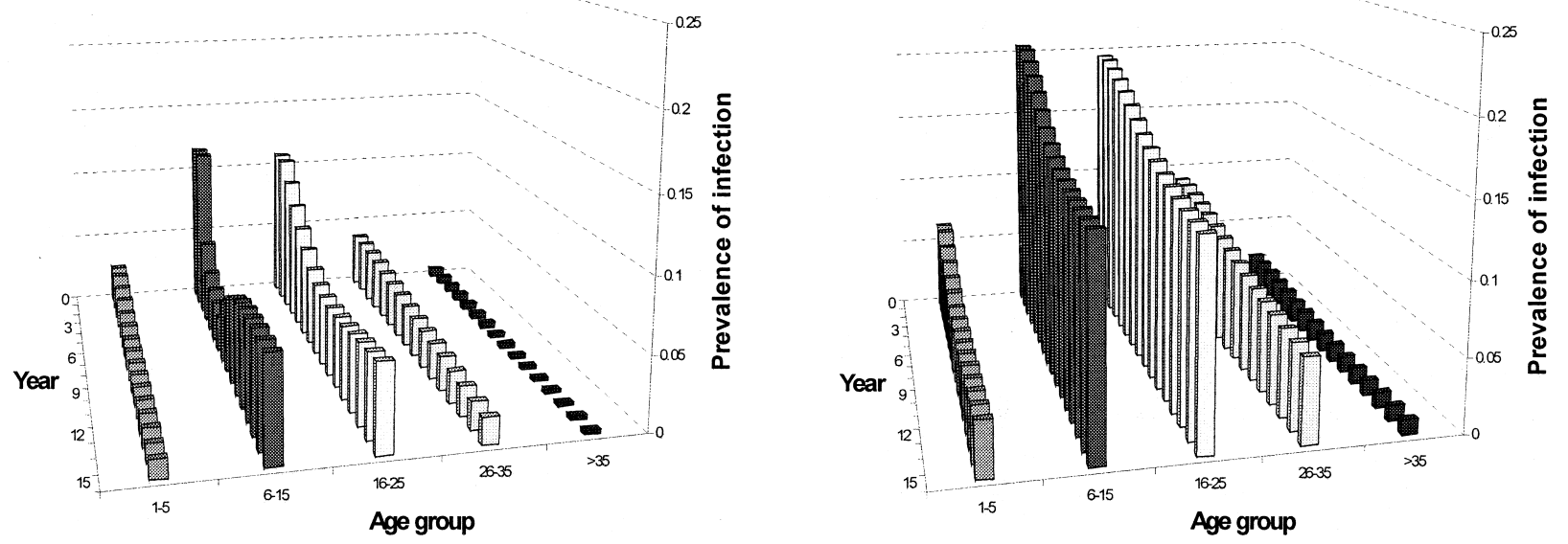

Fig. 1. For legend see opposite. 
Table 2. The proportion of each subgroup treated in the different simulations

\begin{tabular}{|c|c|c|c|c|c|}
\hline \multirow[b]{3}{*}{ Strategy } & \multirow[b]{3}{*}{ Target } & \multicolumn{4}{|l|}{ Population } \\
\hline & & \multicolumn{2}{|c|}{ Children in school } & \multicolumn{2}{|c|}{ Children out-of-school } \\
\hline & & $\begin{array}{l}\text { Coverage } \\
\text { (\% treated) }\end{array}$ & $\begin{array}{l}\text { Age at treatment } \\
\text { (years) }\end{array}$ & $\begin{array}{l}\text { Coverage } \\
\text { (\% treated) }\end{array}$ & $\begin{array}{l}\text { Age at treatment } \\
\text { (years) }\end{array}$ \\
\hline 1 & School & 85 & $6-15$ & 0 & $6-15$ \\
\hline 2 & School-aged & 85 & $6-15$ & 25 & $6-15$ \\
\hline 3 & & 85 & $6-15$ & 50 & $6-15$ \\
\hline 4 & & 85 & $6-15$ & 85 & $6-15$ \\
\hline
\end{tabular}

A unit cost of US $\$ 0.60$ per child treated is assumed for the school-based programme. This is based on recent data on the cost of school-based drug delivery systems in Tanzania and Ghana (Partnership for Child Development, 1999a). Using this unit cost for the school-based strategy, the maximum unit cost for an equivalent effectiveness was assessed for each alternative strategy. The unit cost of the school-based strategy was then varied from US $\$ 0 \cdot 2$ to US $\$ 1.00$ as a form of sensitivity analysis.

RESULTS

\section{Situation at equilibrium}

In the absence of intervention, it can be assumed that there is no change in worm burden through time. This equilibrium situation is used to estimate the transmission parameters, the basic reproductive number in each group $\left(R_{0 g}\right)$ and acts as the basis for evaluating the number of cases that could be prevented after the implementation of a treatment strategy. Fig. 2 illustrates the equilibrium situation for the prevalence of infection and early disease for $S$. mansoni and S. haematobium in females in school (A), males in school (B), females out of school (C) and males out of school (D). This figure clearly shows that the prevalence of infection is highest in school children (aged 6-15 years old), but that the prevalence of early disease tends to be slightly higher in young adults (16 to 25 -year-olds). At equilibrium, males out of school have the highest prevalences of infection and early disease for both schistosome species. This reflects the data observed in Egypt.

\section{Comparison of the effectiveness of alternative control strategies}

Effectiveness is assessed as the (discounted) number of infection or early disease cases prevented over a 15 year time-period from the onset of the first cycle of the annual 5-year treatment programme. The effectiveness of the 4 strategies (school-based and variants on school-aged targeted) is summarized in Table 3. Targeting children in school can achieve between 45 and $77 \%$ of the effectiveness of a schoolaged targeted approach with $85 \%$ coverage; the relative effectiveness depending on the schisotosome species, the measure of effectiveness and the coverage in those not in school. For instance, the relative effectiveness is greater for $S$. mansoni than $S$. haematobium. The difference between the two schistosome species in the number of infection and early disease cases prevented reflects the variations in baseline prevalences and the proportion of children in each group, and the lower rate of development of early disease for $S$. haematobium.

For the area endemic for S. haematobium, the proportion of school-aged children not enrolled in school $(45 \%)$ was higher than in Lower Egypt $(21 \%)$, where S. mansoni is endemic. Reaching these out-of-school children therefore has a greater impact on effectiveness in the case of S. haematobium. For instance, if only $25 \%$ of these children could be reached, effectiveness would increase by over $50 \%$ for $S$. haematobium compared to less than $25 \%$ for $S$. mansoni. If as many as $85 \%$ of the school-age children not enrolled could be treated, the relative effectiveness of the school-aged based programme compared to the school-based programme would increase by more than $100 \%$ for S. haematobium.

\section{Comparison of the unit costs}

Table 4 presents the maximum unit cost for reaching children not in school while achieving the same costeffectiveness as a school-based strategy at a unit cost of US\$0.60. The analysis indicates that one could invest more than US $\$ 0.60$ in treating non-enrolled children and still be more or as cost-effective as a school-based approach. The extra cost available per

Fig. 1. Changes in the prevalence of Schistosoma mansoni (A-D) and Schistosoma haematobium (F-H) infection by age over a period of 15 years as a result of annual school-based treatment (coverage $85 \%$ ) for 5 years. (A) Females in school etc. (B) Males in school. (C) Females out-of-school. (D) Males out-of-school. (E) Females in school etc. (F) Males in school. (G) Females out-of-school. (H) Males out-of-school. 
A
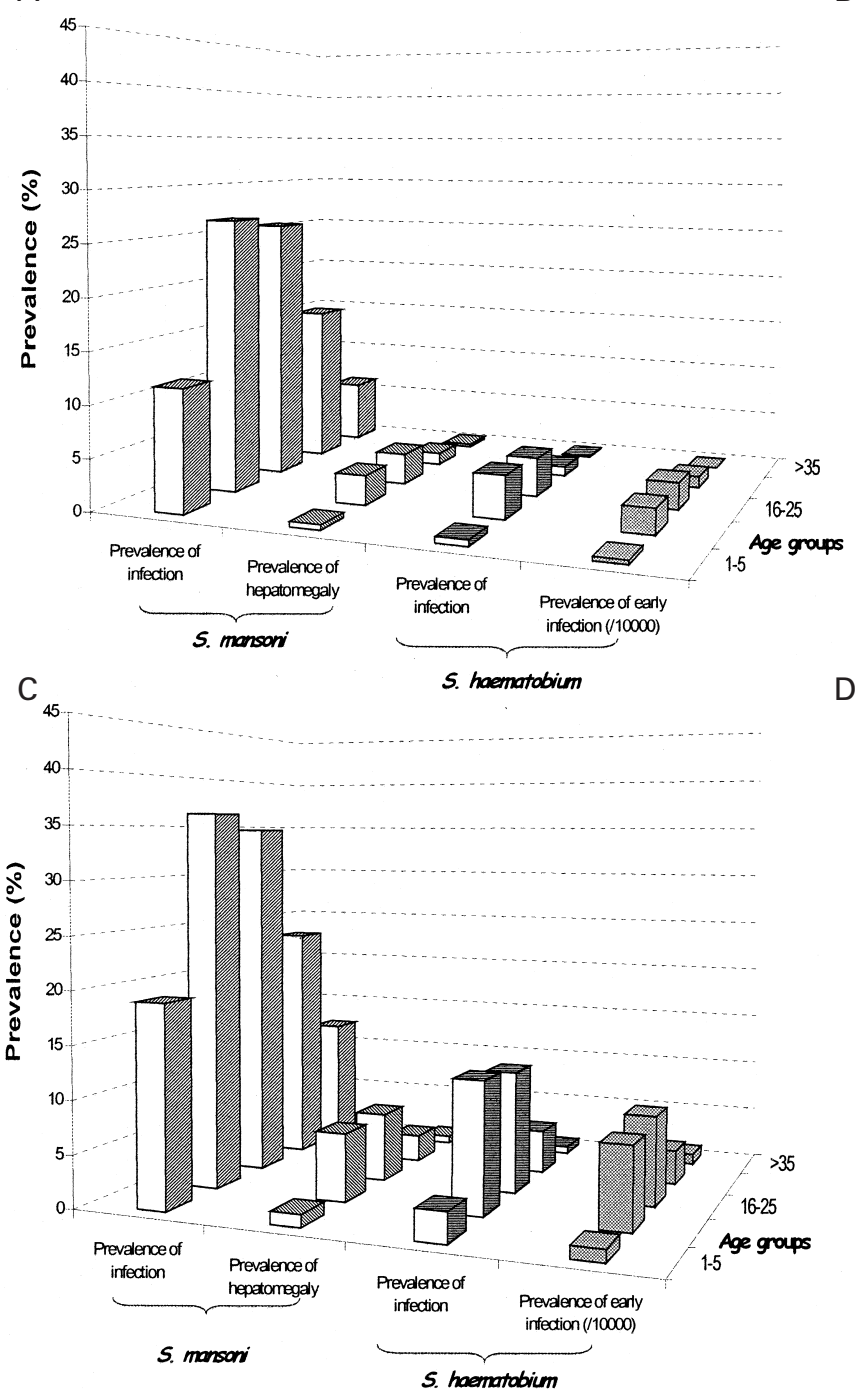

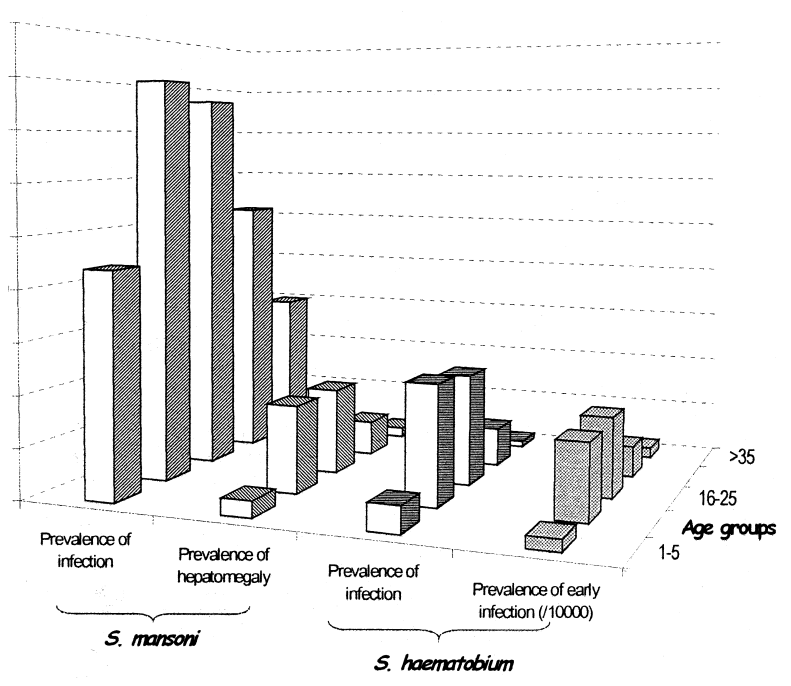

D

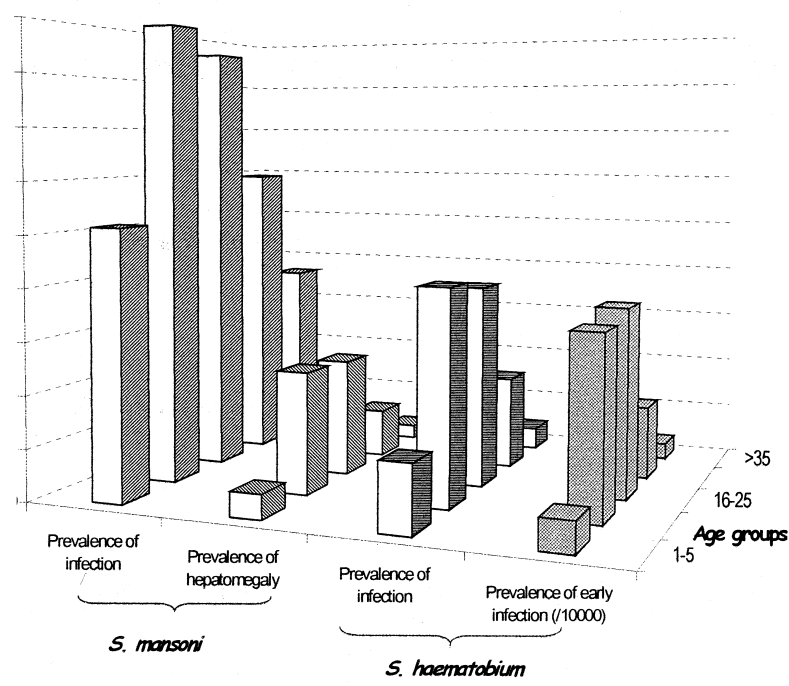

Fig. 2. Equilibrium prevalences for Schistosoma mansoni and Schistosoma haematobium infection and early disease in (A) females in school, (B) males in school, (C) females out-of-school, (D) males out-of-school.

Table 3. The effectiveness of treatment assessed as the discounted infection and early disease cases prevented over a period of 15 years from the first of the 5 annual treatments

\begin{tabular}{|c|c|c|c|c|}
\hline \multirow[b]{2}{*}{ Strategy } & \multicolumn{2}{|l|}{ S. mansoni } & \multicolumn{2}{|c|}{ S. haematobium } \\
\hline & Infection & Early disease & Infection & Early disease \\
\hline 1 & 70764 & 17417 & 20279 & 143 \\
\hline 2 & 86222 & 19966 & 32318 & 223 \\
\hline 3 & 97353 & 21498 & 39682 & 268 \\
\hline 4 & 107117 & 22680 & 44889 & 289 \\
\hline
\end{tabular}

child treated varies with the schistosome species, the measure of effectiveness and the coverage in nonenrolled children.

For S. mansoni, if $25 \%$ of non-enrolled children were treated, one could spend, on top of the US\$ 0.60 which would cover drug costs and minimum delivery costs, an additional US $\$ 1.03$ per child treated (for infection cases prevented) to reach these children. This option would still be more costeffective than a school-based approach. This decreases to US\$ 0.49 for early disease cases prevented. As the coverage increases to $50 \%$ and $85 \%$ in this non-enrolled group, the maximal extra unit cost, in the case of early disease cases prevented, decreases to US\$0.27 and US\$0.06, respectively. This decrease is a result of a reduction in the 
Table 4. The maximum unit cost (US\$) to treat individuals not enrolled in school and achieve the same cost-effectiveness as a school-based strategy (assuming a unit cost of US\$ $0 \cdot 60$ ) and total number of individuals treated for the six strategies

\begin{tabular}{|c|c|c|c|c|c|c|}
\hline \multirow[b]{2}{*}{ Strategy } & \multicolumn{3}{|l|}{ S. mansoni } & \multicolumn{3}{|l|}{ S. haematobium } \\
\hline & Number treated & Infection* & $\begin{array}{l}\text { Early } \\
\text { disease* }\end{array}$ & Number treated & Infection* & $\begin{array}{l}\text { Early } \\
\text { disease* }\end{array}$ \\
\hline 1 & 84522 & {$[0 \cdot 6]$} & {$[0 \cdot 6]$} & 59513 & {$[0 \cdot 6]$} & {$[0 \cdot 6]$} \\
\hline 2 & 91273 & $1 \cdot 64$ & $1 \cdot 10$ & 73618 & $1 \cdot 50$ & 1.42 \\
\hline 3 & 98024 & $1 \cdot 41$ & $0 \cdot 88$ & 87723 & $1 \cdot 21$ & $1 \cdot 11$ \\
\hline 4 & 107475 & $1 \cdot 14$ & $0 \cdot 67$ & 107470 & $1 \cdot 02$ & $0 \cdot 92$ \\
\hline
\end{tabular}

* Maximum unit cost (US\$): this unit cost is the maximum amount one could pay per person in the group of not enrolled individuals (groups 3 and 4) for the strategy to be cost effective as the school-based approach (strategy 1). Effectiveness is measured as infection or early disease case prevented.

difference between the percentage increase in numbers treated and effectiveness of school-aged targeted over school-based approach. This is most pronounced for early disease where the difference is approximately half at $25 \%$ coverage but approaches zero at $85 \%$ (see Fig. 3).

A similar decrease in the extra costs available to reach non-enrolled children as coverage increases is also observed for $S$. haematobium. However, at any given coverage, the maximal unit cost is higher for $S$. haematobium than for S. mansoni when effectiveness is assessed in terms of early disease cases prevented. For instance, at a coverage of $50 \%$, the maximum extra unit cost (for early disease cases prevented) for $S$. haematobium (US\$ $0 \cdot 51$ ) is nearly twice that of the cost for S. mansoni (US\$ 0.28). This is because reaching out-of-school children in the region endemic for $S$. haematobium has a larger relative impact on cases of early disease prevented than numbers treated (see Fig. 3). Interestingly, the results for infection cases prevented suggest that the maximal unit costs are higher for S. mansoni. This observation highlights the importance of the choice of effectiveness measure, particularly for helminths where infection and disease are not linearly related.

The sensitivity analysis showed that with a unit cost as low as US $\$ 0.20$ for the school-based strategy, similar results would have been observed. As the unit cost of the school-based approach increased, the maximal extra unit cost increased for the schoolaged targeted approach.

\section{DISCUSSION}

Concerns have been raised that a large number of school-aged children are missed by school-based programmes because they are not enrolled in school. Estimates of the proportion of children out-ofschool vary by country, locality and sex (United Nations Education, Scientific and Cultural Organization, 1998), but recent studies in Egypt suggest that they can be as high as $45 \%$ (Husein et al. 1996).
These studies also showed that the prevalence of infection was higher in those children not in school. Although treating all school-aged children would increase the proportion of infections treated, it is not clear what the relative effectiveness, in terms of both infection and early disease cases prevented over time would be of employing such an approach over a school-based strategy. Furthermore, since reaching these out-of-school children would likely result in additional costs, the relative cost-effectiveness of these approaches also deserves consideration. This paper presents a first attempt at modelling the possible cost and effectiveness of reaching nonenrolled children through school-age targeted programmes using empirical data from Egypt.

As has been shown in other studies (Bundy et al. 1990; Butterworth et al. 1991; Chan et al. 1995, 1998), targeting treatment at children in school will also reduce infection and disease in the rest of the population (including those non-enrolled). The analysis showed that, for S. mansoni in Lower Egypt, a programme where only $85 \%$ of children attending school were treated would still prevent $77 \%$ of the early disease cases prevented with a programme where $85 \%$ of all school-age children were treated. The corresponding value for $S$. haematobium was $50 \%$, given the lower infection levels and the fewer school-aged children enrolled in Upper Egypt. These results support the implementation of schoolbased approaches, such as those undertaken by the Partnership for Child Development (Partnership for Child Development, 1999b).

However, targeting school-aged children increases the effectiveness of the programme. This also requires that more children be treated. The difference between the increased number of children treated and the increased numbers of infection or disease cases prevented is an important consideration, as total cost rises as more children are treated. The analysis suggested that an approach which targeted school-aged children could have a marked effectiveness advantage over school-based treatment, 

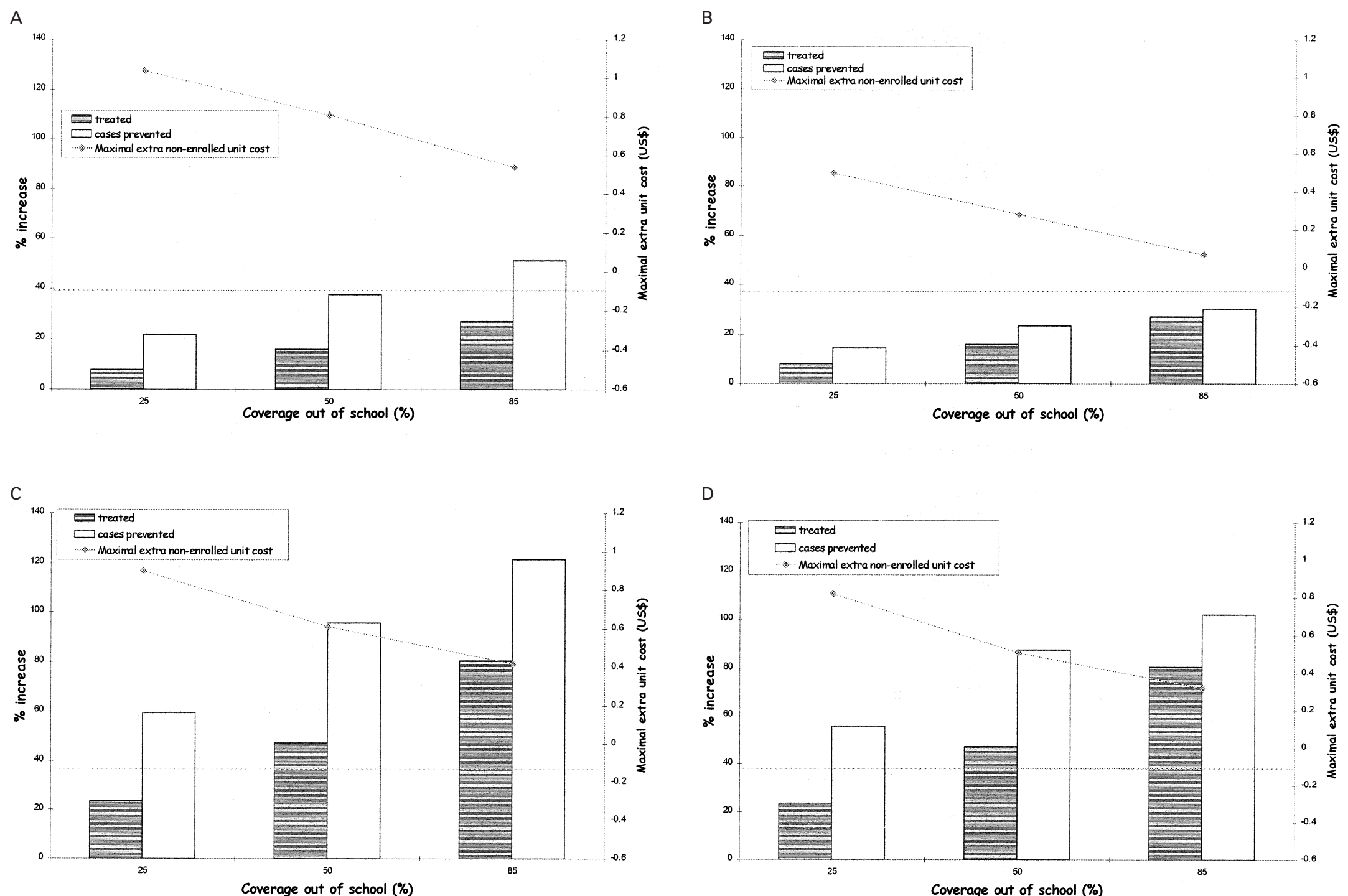

Fig. 3. Relative increase (compared to the school-based strategy) in the number of individuals treated (bar with horizontal lines),

discounted cases prevented after 15 years (bar with vertical lines) and maximum extra unit cost in US\$ (line) for (A) infection with

Schistosoma mansoni, (B) early disease with S. mansoni, (C) infection with S. haematobium, and (D) early disease with S. haematobium. 
and remain more cost-effective even allowing for additional costs in reaching these children. A recent study conducted in an area endemic for $S$. haematobium in Egypt has shown that using advertisement and recruitment of community leaders, teachers and enrolled children to encourage children out of school to attend the school setting for treatment, more than $85 \%$ of these children could be treated. The additional costs involved in reaching these children are not clear, but the analysis here suggests that if $25 \%$ of out-of-school children are treated, more than US $\$ 0.80$ could be used to get this child to the school setting for treatment in the area endemic for $S$. haematobium as this would be more cost-effective than a school-based approach. Importantly, the maximum unit cost available for reaching these children decreases as the coverage increases. However, even at $85 \%$ coverage, an extra US $\$ 0.31$ per child could be invested and this approach would still minimize the cost per early disease case prevented for S. haematobium. Although the same general trends apply to the area endemic for $S$. mansoni, the cost margins are smaller due to the higher school enrolment, and the higher prevalence of infection.

Mathematical models are useful tools for understanding and evaluating the impact of interventions on the disease transmission and dynamics. The population dynamic model used here is based on a set of assumptions regarding transmission rates, immunity, density-dependent effects on worm establishment and the development and resolution of disease. Although the basic model structure and parameter values have been validated with field data (Chan et al. 1995, 1996a,b), this has not been undertaken for the extended school-attendance/ sex/aged-structured model since empirical data on such interventions are lacking. As a result, the analysis presented in this paper should be seen as a first step in modelling the potential cost-effectiveness of reaching non-enrolled children. There are, for instance, a number of limitations in this model. Firstly, individuals are assumed to stay in the same sex/school enrolment group through time. Secondly, the unit of analysis is the age, sex and enrolment group, not the individual. Therefore, there is no estimate of individual contact or factors that might increase or decrease the risk of contact. Including individual risk factors in a refined model might improve the accuracy of the predictions, though this would have to be considered alongside the availability of data on individual risks. Finally, only prevalence data were available to estimate the equilibrium values in this analysis. The model is set up also to receive intensity data, which would be likely to improve the accuracy of the baseline transmission estimates.

This study has shown that treatment of nonenrolled children is an important consideration in maximizing the effectiveness of treatment programmes while still maintaining a cost-effectiveness ratio comparable to school-based delivery. As suggested by Jamison \& Leslie (1990), children in school could have an important role in encouraging their friends and siblings not enrolled to attend the school setting when treatment is offered. Indeed, this analysis has shown that the benefits for the community as a whole may be large enough to warrant extra money being invested in reaching these non-enrolled children. This is not to mention the ethical issue of improving the access to treatment for children that are the most at risk of being highly infected, of low socio-economical status and from the most unfortunate families.

Support was received in the form of personnel awards to Hélène Carabin (Wellcome Trust/Canadian Medical Research Council) and Helen Guyatt (Wellcome Trust).

\section{APPENDIX 1}

\section{The Model}

The mathematical model used in this paper was developed from an earlier age-structured schistosomiasis model (Chan et al. 1995, 1996a, b) by the addition of 4 groups $(g)$ for children in and out of school and males and females. Structurally, the model now involves 4 sets of differential equations, one each for females in school $(g=1)$, males in school $(g=2)$, females out of school $(g=3)$ and males out of school $(g=4)$. The relative sizes of each group are assumed to be constant with age and individuals are assumed to remain in the same group throughout life (this is a restriction of the modelling method) but the coverage of treatment can be varied within each school-attendance group. The proportion of individuals in each group $(g)$ is denoted $\pi(g)$.

The instantaneous change in mean worm burden $(M)$ during very short intervals of calendar time and age for individuals of age $(a)$ at time $(t)$ and in group $(g)$ is given by the partial differential equation that follows the conventions of the earlier models:

$$
\frac{\delta M(g, a, t)}{\delta a}+\frac{\delta M(g, a, t)}{\delta t}=\Lambda(g, a, t) \mathrm{e}^{-\delta I(g, a, t)}-\mu M(g, a, t),
$$

where $I(g, a, t)$ is the level of immunity (modelled in the same way as the previous model with immunity accumulating with experience of infection in group $g$, age $a$ ), $\delta$ is the strength of immunity and $\mu$ is the mortality rate of worms. The immunity factor acts as a modulator for the force of infection (without immunity) represented by $\Lambda(g, a, t)$. The immunity is not lifelong and decays exponentially with age at a 
rate of $\mathrm{e}^{-\mathrm{s}}$ (where $1 / \mathrm{s}$ is the average duration of immunity). In other words, the larger $I(g, a, t)$, the smaller $\mathrm{e}^{-\delta I(g, a, t)}$ which will in turn result in a lower overall acquisition of new infections $(\Lambda(g, a, t)$ $\left.\mathrm{e}^{-\delta(g, a, t)}\right)$.

The force of infection at time $(t)$ for individuals for age (a) in group $(g) \Lambda(g, a, t)$ is shown below:

$$
\begin{aligned}
& \Lambda(g, a, t) \\
& =\frac{\mu R_{0 g} \rho(g, a) f(M(g, a, t)) \sum_{g a} \pi(g, a) \kappa(g, a) M(g, a, t) d a}{\sum_{g a} \pi(g, a) \kappa(g, a) \rho(g, a) d a} .
\end{aligned}
$$

The functions for age-dependent contamination rate $\kappa_{g, a}$, demography $\pi(g, a)$ and density dependence $f(M(g, a, t))$ are calculated in the same way as in the previous models. Using the equilibrium age distribution of infection intensity $M^{*}(g, a)$, the group specific $R_{0 g}$ can be calculated as follows:

$R_{0 g}=\frac{\alpha_{g} \sum \int_{g a} \pi(g, a) \kappa(g, a) \rho(g, a) d a}{\mu \int_{g a} \pi(g, a) \kappa(g, a) M^{*}(g, a) d a}$.

Several parameters in the new model are group specific ( $\pi_{g}$ and $\alpha_{g}$ in the current study because only the prevalence data were available). Since levels of infection may be different in each of the 4 groups, the parameters for the age-specific contact rate are assumed to depend on the group being considered. This value indicates the contact rate at which each individual is exposed to infection. This gives an agegroup specific contact rate (at equilibrium, before treatment) as follows:

$\rho(g, a)=\alpha_{g}\left(a \exp \left(-(\beta a)^{2}\right)+c\right)$,

where $\rho(g, a)$ corresponds to the contact rate for individuals of age $(a)$ in group $(g), \alpha_{g}$ is an intermediate scaling factor, $\beta$ is the contact rate and $c$ is a contact constant. The same numerical value is used for the contamination rate $\kappa(g, a)$, representing the age-group specific rate of contamination of the environment with infectious faeces.
The intermediate scaling factor is determined by the mean worm count at the age of peak intensity of infection $\left(a_{p}\right)$ and the mean worm burden in group $(g)$ as follows:

$\alpha_{g}=\frac{\mu m_{p, g}}{a_{p} \mathrm{e}^{-\beta a_{p} f\left(m_{\rho, g}\right)}}$,

where $a_{p}$ is the age of peak intensity, $m_{p, g}$ is the mean egg count at this peak and for group $(g), \mu$ is the worm death rate, $\beta$ is the inverse of the age of peak contact (assumed to equal 0.125) and

$f\left(m_{p, g}\right)=\left(1+\frac{m_{p, g}}{K\left(m_{p, g}\right)}\left(1-\mathrm{e}^{-\gamma}\right)\right)^{-\left(K\left(m_{p, g}\right)+1\right)}$

is a density-dependence factor. This factor is modelled here as the reduction in the establishment of new adult worms that depends on the current worm load $\left(m_{p, g}\right)$ and on a density dependence constant parameter $(\gamma)$.

The level of infection in each group is input as prevalence of infection from field data. In order to accommodate different distributions of parasite infection in each group, the negative binomial aggregation parameter, $k_{g}$, is also allowed to vary between groups. As with the previous model, a linear relationship between the value of $k_{g}$ and the worm burden is assumed, and both the intercept $\left(k_{0}\right)$ and the slope $\left(k_{l i n}\right)$ of this function can be group dependent. In the current analysis, the intercept and slope are kept constant because no data on the arithmetic mean of epg were available. Nonetheless, since the mean worm burden depends on group $(g)$ and $k_{g}=k_{0}+k_{l i n} * M(g, a), k_{g}$ will vary according to group $(g)$.

As with the previous studies, the differential equations were solved numerically using a FORTRAN computer program. The simulations are initiated with the endemic equilibrium before treatment. The parameters used were the same as in previous studies (Chan et al. 1995, 1996, 1999) unless otherwise stated (see Appendix 2). 
APPENDIX 2

\begin{tabular}{|c|c|c|c|}
\hline Parameter & Symbol (units) & Value & Source \\
\hline \multicolumn{4}{|c|}{ Default parameter set used for simulations of $S$. mansoni } \\
\hline Concomitant immunity & $\gamma$ & $0 \cdot 005$ & Chan et al. (1995) \\
\hline Immunity strength & $\delta$ & $0 \cdot 001$ & Chan et al. $(1996 b)$ \\
\hline Immunity duration & $1 /$ s (years) & 10 & Chan et al. $(1996 b)$ \\
\hline Maximum human age & A (years) & 80 & Estimated \\
\hline Age at peak contamination & $1 / \theta($ years $)$ & $14 \cdot 29$ & Present analysis \\
\hline Age at peak contact & $1 / \beta$ (years) & $14 \cdot 29$ & Present analysis \\
\hline Contact constant & $\mathrm{C}$ & $0 \cdot 35$ & Present analysis \\
\hline Timestep & Years & $0 \cdot 05$ & Present analysis \\
\hline Maximum worm burden & & 2000 & Cheever (1968) \\
\hline Demographic constants & $b e^{-d a}$ & $\begin{array}{l}b=0.0356 \\
d=0.033\end{array}$ & World Bank data [ ] \\
\hline Aggregation parameter (intercept) & $k_{0}$ & $0 \cdot 132$ & Chan et al. (1995) \\
\hline Aggregation parameter (slope) & $k_{l i n}$ & $0 \cdot 002$ & Chan et al. (1995) \\
\hline Epg per worm & $\mathrm{e}_{I} \operatorname{lin}$ & $5 \cdot 26$ & Chan et al. (1995) \\
\hline Worm life-span & $1 / \mu($ years $)$ & 4 & Anderson \& May (1991) \\
\hline Development rate early disease & $\lambda_{\mathrm{e}}$ & $0 \cdot 0071$ & Chan et al. $(1996 a)$ \\
\hline Resolution rate early disease & $\mu_{\mathrm{e}}$ & 1 & Chan et al. $(1996 a)$ \\
\hline Development rate late disease & $\lambda_{l}$ & $0 \cdot 015$ & Chan et al. $(1996 a)$ \\
\hline Resolution rate late disease & $\mu_{l}$ & $0 \cdot 0769$ & Chan et al. $(1996 a)$ \\
\hline Threshold for heavy infection & (eggs per gram) & 200 & Present analysis \\
\hline \multicolumn{4}{|l|}{ Group-specific parameters } \\
\hline \multicolumn{4}{|l|}{ Proportion of the population } \\
\hline Females in school & $\pi(g=1)$ & $0 \cdot 3582$ & Husein et al. (1996) \\
\hline Males in school & $\pi(g=2)$ & $0 \cdot 4282$ & Husein et al. (1996) \\
\hline Females out of school & $\pi(g=3)$ & $0 \cdot 1318$ & Husein et al. (1996) \\
\hline Males out of school & $\pi(g=4)$ & $0 \cdot 0818$ & Husein et al. (1996) \\
\hline \multicolumn{4}{|l|}{ Scaling factor* } \\
\hline Females in school & $\alpha(g=1)$ & $0 \cdot 2469$ & Present analysis \\
\hline Males in school & $\alpha(g=2)$ & $0 \cdot 8253$ & Present analysis \\
\hline Females out of school & $\alpha(g=3)$ & $0 \cdot 5979$ & Present analysis \\
\hline Males out of school & $\alpha(g=4)$ & $1 \cdot 2154$ & Present analysis \\
\hline
\end{tabular}

* Scaling factor: $\alpha(g)=\frac{\mu m_{p, g}}{a_{p} \mathrm{e}^{-\beta a_{p} f\left(m_{p, g}\right)}}$

where $a_{p}$ is the age of peak intensity, $m_{p, g}$ is the mean egg count at this peak and for group (g), $\mu$ is the worm death rate, $\beta$ is the inverse of the age of peak contact (assumed equal to $0 \cdot 125$ ),

$f\left(m_{p, g}\right)=\left(1+\frac{m_{p, g}}{K\left(m_{p, g}\right)}\left(1-\mathrm{e}^{-\gamma)}\right)\right)^{-\left(K\left(m_{p, g}\right)+1\right)}$ and $K\left(m_{p, g}\right)=k_{0}+k_{l i n} * m_{p, g}$. 
APPENDIX 2 (cont.)

\begin{tabular}{|c|c|c|c|}
\hline Parameter & Symbol (units) & Value & Source \\
\hline \multicolumn{4}{|c|}{ Default parameter set used for simulations of $S$. haematobium } \\
\hline Concomitant immunity & $\gamma$ & $0 \cdot 001$ & Chan et al. (1995) \\
\hline Immunity strength & $\delta$ & $0 \cdot 001$ & Chan et al. $(1996 b)$ \\
\hline Immunity duration & $1 / \mathrm{s}$ (years) & 10 & Chan et al. $(1996 b)$ \\
\hline Maximum human age & A (years) & 80 & Estimated \\
\hline Age at peak contamination & $1 / \theta$ (years) & $14 \cdot 29$ & Present analysis \\
\hline Age at peak contact & $1 / \beta$ (years) & $14 \cdot 29$ & Present analysis \\
\hline Contact constant & $\mathrm{C}$ & $0 \cdot 35$ & Present analysis \\
\hline Timestep & Years & $0 \cdot 05$ & Present analysis \\
\hline Maximum worm burden & & & Cheever (1968) \\
\hline Demographic constants & $b e^{-d a}$ & $\begin{array}{l}b=0.0356 \\
d=0.033\end{array}$ & World Bank data [ ] \\
\hline Aggregation parameter (intercept) & $k_{0}$ & $0 \cdot 184$ & Chan et al. (1996a) \\
\hline Aggregation parameter (slope) & $k_{l i n}$ & $0 \cdot 0002$ & Chan et al. $(1996 a)$ \\
\hline Eggs per $\mathrm{ml}$ per worm & $\mathrm{e}_{I}^{l n}$ & 1 & Chan et al. (1995) \\
\hline Worm life-span & $1 / \mu($ years $)$ & 4 & Anderson \& May (1991) \\
\hline Development rate early disease & $\lambda_{\mathrm{e}}$ & $0 \cdot 001$ & Chan et al. (1996a) \\
\hline Resolution rate early disease & $\mu_{\mathrm{e}}$ & 1 & Chan et al. (1996a) \\
\hline Development rate late disease & $\lambda_{l}$ & $0 \cdot 04$ & Chan et al. $(1996 a)$ \\
\hline Resolution rate late disease & $\mu_{l}$ & $0 \cdot 1$ & Chan et al. $(1996 a)$ \\
\hline Threshold for heavy infection & (eggs per $10 \mathrm{ml})$ & 50 & Present analysis \\
\hline \multicolumn{4}{|l|}{ Group-specific parameters } \\
\hline \multicolumn{4}{|l|}{ Proportion of the population } \\
\hline Females in school & $\pi(g=1)$ & $0 \cdot 1829$ & Husein et al. (1996) \\
\hline Males in school & $\pi(g=2)$ & $0 \cdot 3709$ & Husein et al. (1996) \\
\hline Females out of school & $\pi(g=3)$ & $0 \cdot 2928$ & Husein et al. (1996) \\
\hline Males out of school & $\pi(g=4)$ & $0 \cdot 1535$ & Husein et al. (1996) \\
\hline \multicolumn{4}{|l|}{ Scaling factor* } \\
\hline Females in school & $\alpha(g=1)$ & $0 \cdot 015$ & Present analysis \\
\hline Males in school & $\alpha(g=2)$ & $0 \cdot 0429$ & Present analysis \\
\hline Females out of school & $\alpha(g=3)$ & $0 \cdot 0462$ & Present analysis \\
\hline Males out of school & $\alpha(g=4)$ & $0 \cdot 1010$ & Present analysis \\
\hline
\end{tabular}

* Scaling factor: $\alpha(g)=\frac{\mu m_{p, g}}{a_{p} \mathrm{e}^{-\beta a_{p}} f\left(m_{p, g}\right)}$

where $a_{p}$ is the age of peak intensity, $m_{p, g}$ is the mean egg count at this peak and for group (g), $\mu$ is the worm death rate, $\beta$ is the inverse of the age of peak contact (assumed equal to $0 \cdot 125$ ),

$f\left(m_{p, g}\right)=\left(1+\frac{m_{p, g}}{K\left(m_{p, g}\right)}\left(1-\mathrm{e}^{-\gamma)}\right)\right)^{-\left(K\left(m_{p, g}\right)+1\right)}$ and $K\left(m_{p, g}\right)=k_{0}+k_{l i n} * m_{p, g}$.

\section{REFERENCES}

ANDERSON, R. M. \& MAY, R. M. (1985). Helminth infections of human: mathematical models, population dynamics and control. Advances in Parasitology 24, $1-101$.

ANDERSON, R. M. \& MAY, R. M. (1991). Infectious Disease of Humans: Dynamics and Control, 2nd Edn. Oxford University Press, Oxford.

Barakat, R., FARghaly, A., El MaSry, A. G., ELSAYED, M. K., HUSEIN, M. H. \& DEWOLFE MilleR, F. (1995). Schistosoma mansoni in the Nile delta, Egypt. A large scale epidemiological study in Kafr El Sheikh Governorate. Tropical and Geographical Medicine 47, 259-265.

BUNDY, D. A. P., WONG, M. S., LEWIS, L. L. \& HORTON, J. (1990). Control of geohelminths by delivery of targeted chemotherapy through schools. Transactions of the Royal Society of Tropical Medicine and Hygiene 84, 115-120.
BUTTERWORTH, A. E., STURROCK, R. F., OUMA, J. H., MBUGUA, G. G., FULFORD, A. J., KARIUKi, H. C. \& KOECH, D. (1991). Comparison of different chemotherapy strategies against Schistosoma mansoni in Machakos District, Kenya: effects on human infection and morbidity. Parasitology 103, 339-355.

CHAN, M.-S. \& BUNDY, D. A. P. (1997). Modelling the dynamic effects of community chemotherapy on patterns of morbidity due to Schistosoma mansoni. Transactions of the Royal Society of Tropical Medicine and Hygiene 91, 216-220.

CHAN, M.-S., ANDERSON, R. M., MEDLEY, G. F. \& BUNDY, D. A. P. (1996a). Dynamic aspects of morbidity and acquired immunity in schistosomiasis control. Acta Tropica 62, 105-117.

CHAN, M.-S., GUYATT, H. L., BUNDY, D. A. P. \& MEDLEy, G. F. (1994). The development and validation of an age-structured model for the evaluation of disease control strategies for intestinal helminths. Parasitology 109, 389-396. 
CHAN, M.-S., GUYATT, H. L., BUNDY, D. A. P. \& MEDLEY, G. F. $(1996 b)$. Dynamic models of Schistosomiasis morbidity. American Fournal of Tropical Medicine and Hygiene 55, 52-62.

CHAN, M.-S., GUYATt, H. L., BUNDY, D. A. P., BOоTH, M., FUlFord, A. J. C. \& MEDLEY, G. F. (1995). The development of an age structured model for schistosomiasis transmission dynamics and control and its validation for Schistosoma mansoni. Epidemiology and Infection 115, 325-344.

CHAN, M. S., NSOWAH-NUAMAH, N. N. N., ADJEI, S., WEN, S. T., Hall, A. \& BUNDY, D. A. P. (1998). Predicting the impact of school-based treatment of urinary schistosomiasis given by the Ghana Partnership for Child Development. Transactions of the Royal Society of Tropical Medicine and Hygiene 92, 386-389.

CHEEVER, A. W. (1968). A quantitative post-mortem study of Schistosoma mansoni in man. American Fournal of Tropical Medicine and Hygiene 17, 38-64.

EL KНOBY, T., GALAL, N. \& FENWICK, A. (1998). The USAID/Government of Egypt's Schistosomiasis Research Project (SRP). Parasitology Today 14, 92-96.

GUYATT, H. (1998). Different approaches to modelling the cost-effectiveness of schistosomiasis control. Memorias del Instituto Oswaldo Cruz, Rio de Fainero 93, 75-84.

GUYATT, H. L. (1999). Mass chemotherapy and schoolbased antihelminthic delivery. Transactions of the Royal Society of Tropical Medicine and Hygiene 93, $12-13$.

GUYATT, H. L. \& CHAN, M.-S. (1998). An investigation into the interaction between drug efficacy and drug price of praziquantel in determining the cost-effectiveness of school-targeted treatment for Schistosoma mansoni using a population dynamic model. Tropical Medicine and International Health 3, 425-435.

Gyorkos, T. W., CAMara, B., Kokoskim, E., CARABim, H. \& PRouty, R. (1995). Enquête de prévalence parasitaire chez les enfants d'âge scolaire en Guinée-Comakry. Cahiers Santé 6, 377-381.

HAMMAD, T. A., GABR, N. S., HUSEIN, M. H., ORIEBY, A., SHAWKY, E. \& STRICKLAND, G. T. (1997). Determinants of infection with schistosomiasis haematobia using logistic regression. American Fournal of Tropical Medicine and Hygiene 57, 454-458.

HALl, A., ORINDA, V., BUNDY, D. A. P. \& BROUN, D. (1997). Promoting child health through helminth control - a way forward? Parasitology Today 13, 411-413.
HUSEIN, M. H., TALAAT, M., EL-SAYED, M. K., EL-BADAWI, A. \& EVANS, D. B. (1996). Who misses out with schoolbased health programmes? A study of schistosomiasis control in Egypt. Transactions of the Royal Society of Tropical Medicine and Hygiene 90, 362-365.

JAMISON, D. T. \& LESLIE, J. (1990). Health and nutrition considerations in education planning. 2. The cost and effectiveness of school-based interventions. Food and Nutrition Bulletin 12, 204-214.

MONTESOR, A., URBANi, C., CAMARA, B., BHA, A. B., Albonico, M. \& SAVIOLi, L. (1997). Enquête préliminaire á la mise en place d'un programme de santé scolaire en Guinée. Médecine Tropicale 57, 294-298.

murray, C. J. L. (1996). Global Burden of Disease. Harvard University Press, Cambridge, Mass.

NOKES, C. \& BUNDY, D. A. P. (1993). Compliance and absenteeism in school children: implications for helminth control. Transactions of the Royal Society of Tropical Medicine and Hygiene 87, 148-152.

PARTNERSHIP FOR CHILD DEVELOPMENT (1997). Better health, nutrition and education for the school-aged child. Transactions of the Royal Society of Tropical Medicine and Hygiene 91, 1-2.

PARTNERSHIP FOR CHILD DEVELOPMENT (1999a). The cost of large-scale school health programmes which deliver anthelminthics to children in Ghana and Tanzania. Acta Tropica 73, 183-204.

PARTNERShip FOR CHILd DEVElopment (1999b). Available from URL: http://www.ceid.ox.ac.uk/child/ Home.htm.

SAVioli, L., RENGanathan, E., MONTESor, A., Davis, A. \& BEHBEhani, K. (1997). Control of schistosomiasis - a global picture. Parasitology Today 13, 444-448.

TAlaAt, M., omar, M. \& EVANS, D. (1999). Developing strategies to control schistosomiasis morbidity in nonenrolled school-aged children: experience from Egypt. Tropical Medicine and International Health 4, 551-556.

UNITED NATIONS EDUCATION, SCIENTIFIC AND CULTURAL ORgANiZATION (1998). UNESCO Yearbook 1998. Available from URL: http://unescostat.unesco.org// Yearbook/

USEH, M. F. \& EJEZIE, G. C. (1999). School-based schistosomiasis control programmes: a comparative study on the prevalence and intensity of urinary schistosomiasis among Nigerian school-aged children in and out of school. Transactions of the Royal Society of Tropical Medicine and Hygiene 93, 387-391. 